\title{
Antibiotic and heavy-metal resistance of Vibrio parahaemolyticus isolated from fresh shrimps in Shanghai fish markets, China
}

\author{
Yu He ${ }^{1} \cdot$ Lanlan Jin $^{1} \cdot$ Fengjiao Sun ${ }^{1} \cdot$ Qiongxia Hu $^{1} \cdot \operatorname{Lanming~Chen~}^{1}$
}

Received: 20 November 2015 / Accepted: 3 April 2016 / Published online: 16 April 2016

(C) The Author(s) 2016. This article is published with open access at Springerlink.com

\begin{abstract}
Vibrio parahaemolyticus is a causative agent of human serious seafood-borne gastroenteritis disease and even death. Shrimps, often eaten raw or undercooked, are an important reservoir of the bacterium. In this study, we isolated and characterized a total of $400 \mathrm{~V}$. parahaemolyticus strains from commonly consumed fresh shrimps (Litopenaeus vannamei, Macrobrachium rosenbergii, Penaeus monodon, and Exopalaemon carinicauda) in Shanghai fish markets, China in 2013-2014. The results revealed an extremely low occurrence of pathogenic $V$. parahaemolyticus carrying two major toxic genes ( $t d h$ and $t r h, 0.0$ and $0.5 \%$ ). However, high incidences of antibiotic resistance were observed among the strains against ampicillin (99\%), streptomycin (45.25\%), rifampicin $(38.25 \%)$, and spectinomycin $(25.50 \%)$. Approximately $24 \%$ of the strains derived from the P. monodon sample displayed multidrug resistant (MDR) phenotypes, followed by 19,12 , and $6 \%$ from the $E$. carinicauda, $L$. vannamei, and $M$. rosenbergii samples, respectively. Moreover, tolerance to heavy metals of $\mathrm{Cr}^{3+}$ and $\mathrm{Zn}^{2+}$ was observed in 90 antibiotic resistant strains, the majority of which also displayed resistance to $\mathrm{Cu}^{2+}(93.3 \%), \mathrm{Pb}^{2+}$ $(87.8 \%)$, and $\mathrm{Cd}^{2+}(73.3 \%)$. The pulsed-field gel electrophoresis (PFGE)-based genotyping of these strains revealed a
\end{abstract}

Responsible editor: Kenneth Mei Yee Leung

$\mathrm{Yu} \mathrm{He}$ and Lanlan Jin contributed equally to this work.

Lanming Chen

lmchen@shou.edu.cn

1 Key Laboratory of Quality and Safety Risk Assessment for Aquatic Products on Storage and Preservation (Shanghai), China Ministry of Agriculture, College of Food Science and Technology, Shanghai Ocean University, 999 Hu Cheng Huan Road, Shanghai 201306, Peoples' Republic of China total of 71 distinct pulsotypes, demonstrating a large degree of genomic variation among the isolates. The wide distribution of MDR and heavy-metal resistance isolates in the PFGE clusters suggested the co-existence of a number of resistant determinants in $V$. parahaemolyticus population in the detected samples. This study provided data in support of aquatic animal health management and food safety risk assessment in aquaculture industry.

Keywords Vibrio parahaemolyticus · Aquatic products . Virulence $\cdot$ Antimicrobial resistance $\cdot$ Heavy metal resistance . Pulsed-field gel electrophoresis

\section{Introduction}

China has become the world's largest producer of aquatic products since 2002 (People's Republic of China, Fishery Products Annual Report). Along with the fast growing aquaculture industry, however, aquatic animal diseases have also rapidly increased (Wu et al. 2014). Antimicrobial agents are commonly used in the animal breeding industry and effectively prevent disease outbreaks caused by pathogenic microorganism. Nevertheless, the inappropriate usage of antimicrobial drugs in aquaculture contributed to the development of antibiotic-resistant bacteria and imposed serious problems on aquatic ecosystems, particularly in the developing countries (Woolhouse and Farrar 2014). For example, the high incidences of resistance to antimicrobial agents such as ampicillin, rifampicin, and streptomycin have been reported in V. parahaemolyticus isolates originated from some aquatic products in Asian and European countries, e.g., southern China (Xie et al. 2015), Korea (Kang et al. 2015), Poland (Lopatek et al. 2015), and Italy (Ottaviani et al. 2013). On the other hand, in addition to increasing industrialization, environmental pollution has become one of the most challenging issues in the developing 
countries. High occurrence of heavy metal resistant bacteria has been detected in various environments, e.g., marine, river and agricultural soil (Sabry et al. 1997; Ansari et al. 2008; Malik and Aleem 2011). Contaminated water with industrial pollutants (e.g., heavy metals) was supposed to enhance the selection for antibiotic resistance and vice versa (An et al. 2010; Matyar 2012; Zhao et al. 2012).

V. parahaemolyticus is a Gram-negative, halophilic bacterium that thrives in marine, estuarine, and aquaculture environments worldwide (Broberg et al. 2011; Letchumanan et al. 2014). The bacterium is a causative agent of serious human seafood-borne gastroenteritis disease and even death (Boyd et al. 2008; Ceccarelli et al. 2013). In China, the incidence of food-borne illnesses caused by consumption of aquatic products contaminated with $V$. parahaemolyticus has become one of the most important food safety risk, particularly in the southeast littoral provinces (Wang et al. 2007; Chen et al. 2010). Shrimps, often eaten raw or undercooked, are an important reservoir of $V$. parahaemolyticus. To date, numerous studies have been conducted to characterize $V$. parahaemolyticus from clinical samples in different parts of the world (e.g., Boyd et al. 2008; Broberg et al. 2011; Ceccarelli et al. 2013; Tsai et al. 2013; Letchumanan et al. 2014); nevertheless, insufficient information is available on the isolates from aquaculture products, such as various shrimps in China (e.g., Chen et al. 2012; Song et al. 2013; $\mathrm{Xu}$ et al. 2014; Albuquerque Costa et al. 2015; Xie et al. 2015). Thus, in this study, we aimed to determine antibiotic and heavy-metal resistance of the $400 \mathrm{~V}$. parahaemolyticus strains isolated from four types of fresh shrimps commonly consumed in Shanghai, China, in order to address the lack of molecular ecological data of the bacterium in aquaculture products.

\section{Materials and methods}

\section{Sample collection}

The fresh shrimps, including L. vannamei, M. rosenbergii, P. monodon, and E. carinicauda, were collected monthly from Shanghai fish markets in Shanghai, China from June to November in 2013 and 2014. The former three are widely cultured in the southeast littoral provinces in China, while the latter is a type of small shrimp grown in Shanghai and neighboring areas. The L. vannamei (known as Pacific white shrimp) is the most widely cultured and productive alien crustacean worldwide. It is native to the western Pacific coast of Latin America and introduced commercially since 1996 into China and several countries in Asia. The freshwater culture of L. vannamei has proven even more successful than brackish water culture conditions (Tang et al. 2014). M. rosenbergii (known as the giant river prawn) is the most important cultured freshwater prawn in the world. It is native to the Indo-Pacific region, northern Australia, and Southeast Asia, and now farmed on a large scale in many countries (Sahul Hameed and Bonami 2012). P. monodon (known as the black tiger shrimp) is a marine crustacean especially widely cultured in its natural distribution region of Indo-Pacific (Nunan et al. 2005). E. carinicauda is widely distributed in the East China Sea. It is one of the major economic shrimp species cultured in China (Zhang et al. 2015). The samples stored in sterile plastic bags (Shanghai Sangon Biological Engineering Technology and Services Co., Ltd., Shanghai, China) were immediately transported in icebox to our laboratory at Shanghai Ocean University in Shanghai, China for experiments.

\section{Isolation and identification of $V$ parahaemolyticus isolates}

$V$. parahaemolyticus was isolated and identified according to the instructions of the Chinese Government Standard (GB17378-2007) and the Standard of the Bacteriological Analytical Manual of the US Food and Drug Administration (8th Edition, Revision A, 1998) (Song et al. 2013). Briefly, aliquots (25 g) of each shrimp sample were individually homogenized in appropriate volumes of alkaline peptone water (APW, Beijing Land Bridge Technology Co., Ltd., Beijing, China) using the lab blender BagMixer (Interscience, Paris, France). Microbial cells in supernatant were appropriately diluted and spread on the CHROMagar ${ }^{\mathrm{TM}}$ Vibrio (CHROMagar, Paris, France) or thiosulfate citrate bile salts sucrose (TCBS, Beijing Land Bridge Technology Co., Ltd., Beijing, China) agar plates. The plates were incubated at $37^{\circ} \mathrm{C}$ for $24 \mathrm{~h}$. Colonies were picked out, screened, and identified according to the method described previously (Song et al. 2013). Genomic DNA preparation, oligonucleotide primer synthesis, PCR reactions and sequence analysis were performed as previously described (Song et al. 2013; Tang et al. 2014). The virulence genes ( $t d h$ and $t r h$ ) were detected by PCR as previously described (Song et al. 2013). $V$. parahaemolyticus ATCC33847 $\left(t d h^{+} t r h^{-}\right)$(Fujino et al. 1965) and ATCC17802 ( $\left.t d h^{-} t r h^{+}\right)$(Baumann et al. 1973), isolated from clinical and food-poisoning cases, respectively, were used as positive control strains as described previously (He et al. 2015).

\section{Susceptibility to antimicrobial agents and heavy metals}

$V$. parahaemolyticus isolates were measured for in vitro susceptibility to ten antimicrobial agents using Kirby-Bauer disk diffusion method according to the Clinical and Laboratory Standards Institute (CLSI, 2006, Approved Standard-Ninth Edition, M2-A9, Vol. 26 No. 1) (Song et al. 2013). MuellerHinton agar medium (Oxoid, UK) and the disks with antimicrobial agents (Oxoid, UK) were used in this study, including 10- $\mu \mathrm{g}$ ampicillin (AMP), 30- $\mu \mathrm{g}$ chloramphenicol (CHL), 
10- $\mu \mathrm{g}$ streptomycin (STR), 10- $\mu \mathrm{g}$ gentamicin (CN), 30- $\mathrm{gg}$ kanamycin (KAN), 5- $\mu$ g rifampicin (RIF), 100- $\mu$ g spectinomycin (SPT), 30- $\mu \mathrm{g}$ tetracycline (TET), 5- $\mu \mathrm{g}$ trimethoprim (TM), and 25- $\mu \mathrm{g}$ SXT (sulfamethoxazole (23.75 $\mu \mathrm{g}$ )-trimethoprim $(1.25 \mu \mathrm{g}))$. Susceptible, intermediate, and or resistant phenotypes were reported according to the established breakpoints for $V$. parahaemolyticus. In the case of the lacking of the established breakpoints of some antimicrobial agents for the bacterium, the values for Vibrio cholerae or enterobacteriaceae were referred. To date, no standard method is available to measure bacterial susceptibility to heavy metals. Tolerance of the isolates to heavy metals was determined according to the method described previously (Malik and Aleem 2011; Song et al. 2013). The minimal inhibitory concentration (MIC) in vitro of the tested heavy metals against the isolates was measured quantitatively using Broth Dilution Testing (microdilution) (CLSI, 2006). The heavy metals used in this study included $\mathrm{NiCl}_{2}, \mathrm{CrCl}_{3}, \mathrm{CdCl}_{2}, \mathrm{PbCl}_{2}, \mathrm{CuCl}_{2}, \mathrm{ZnCl}_{2}$, $\mathrm{MnCl}_{2}$, and $\mathrm{HgCl}_{2}$ [Analytical Reagent (AR), Sinopharm Chemical Reagent Co., Ltd, Shanghai, China]. The assays were performed in triplicate experiments, and quality control strains of Escherichia coli ATCC25922 and K12 were purchased from the Institute of Industrial Microbiology (Shanghai, China), and used in the antibiotic and heavy-metal resistance tests, respectively (Malik and Aleem 2011; Song et al. 2013).

\section{PFGE-based genotyping analysis}

The PFGE analysis was performed according to the method described previously (He et al. 2015). Genomic DNA fragments digested with the restriction endonuclease NotI (Japan TaKaRa BIO, Dalian Company, Dalian, China) were resolved in a CHEF Mapper system (Bio-Rad Laboratories, Hercules, Calif., USA). Chromosome DNA of Salmonella enterica strain H9812 was digested with the restriction endonuclease XbaI (Japan TaKaRa BIO, Dalian Company, Dalian, China) and used as DNA molecular markers ranging from 20.5 to $1,135 \mathrm{~kb}$. PFGE patterns were analyzed using the NTSYSpc 2.10e Software according to the unweighted pair group method with arithmetic mean based on Dice coefficients.

\section{Results and discussion}

\section{Virulence of the $V$. parahaemolyticus isolates}

L. vannamei, $M$. rosenbergii, $P$. monodon, and $E$. carinicauda are very common shrimps consumed in Shanghai, China. Pure culture of randomly selected $100 \mathrm{~V}$. parahaemolyticus strains isolated from each type of the shrimps was analyzed in this study. Pathogenic $V$. parahaemolyticus produces two major toxic proteins, thermostable direct haemolysin (TDH) and TDH-related haemolysin (TRH), which play a crucial role in the diarrhea disease elicited by the bacterium (Boyd et al. 2008). In this study, a total of $400 \mathrm{~V}$. parahaemolyticus strains were subjected to the detection of the two virulence-associated genes by PCR. The results revealed that all the isolates were featured with no toxic $t d h$ gene. However, the trh gene was detected positive from two isolates derived from $L$. vannamei and $P$. monodon, respectively. The very low occurrence of pathogenic $V$. parahaemolyticus has also been reported from the majority of non-clinical samples previously (e.g., Chao et al. 2009; Song et al. 2013; Haley et al. 2014).

\section{Susceptibility of the $V$. parahaemolyticus isolates to antimicrobial agents}

Antimicrobial susceptibility of the $400 \mathrm{~V}$. parahaemolyticus isolates was determined, and ten antimicrobial agents were tested. As illustrated in Fig. 1, all the isolates were susceptible to CHL and TET. Of these, a total of 35 strains showed non-resistance to all the ten drugs. Since 2002, CHL, its salts and esters (including cholramphenicol succinate) have been banned to use in breeding industry in China (China Department of Agriculture, Bulletin No. 193), which may serve as an explanation of the result in this study. Our observation correlated with a recent report (Xie et al. 2015), showing that all $150 \mathrm{~V}$. parahaemolyticus isolates in aquatic products collected from South China markets were also susceptible to CHL. Albeit the wide usage of TET, sulfonamides and quinolones in aquaculture has been reported (Holmström et al. 2003), the resistance to TET was not detected from all the $V$. parahaemolyticus isolates in this study. In contrast, consistent with the previous studies (Matyar 2012; Song et al. 2013; Kang et al. 2015), AMP resistance was the most predominant (99\%) among the isolates examined in this study. Moreover, the

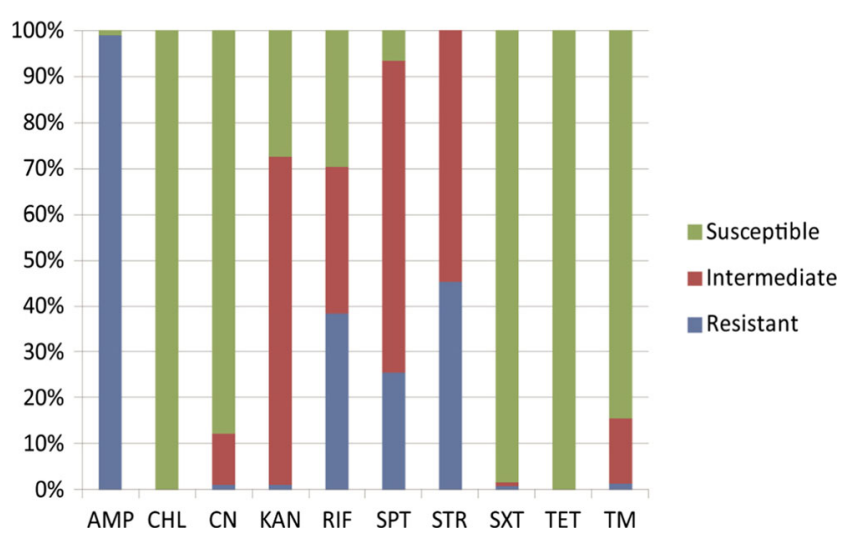

Fig. 1 Antimicrobial susceptibility of the four hundred $V$. parahaemolyticus strains isolated from the fresh shrimp samples collected in Shanghai fish markets in 2013-2014. AMP ampicillin, $C H L$ chloramphenicol, $C N$ gentamicin, KAN kanamycin, RIF rifampicin, $S P T$ spectinomycin, $S T R$ streptomycin, $S X T$ sulfamethoxazole-trimethoprim, $T E T$ tetracycline, $T M$ trimethoprim 
resistance of the isolates to the other antimicrobial agents was also observed, including STR (45.3\%), RIF (38.3\%), and SPT $(25.5 \%)$. Meanwhile, the isolates showed high levels of intermediate susceptibilities to these three drugs (Fig. 1). High incidences of resistance to STR $(88.7,50.7 \%$ ) have recently been reported in V. parahaemolyticus isolates originating from aquatic products in China (Xie et al. 2015) and Korea (Kang et al. 2015) as well. The STR-resistant $V$.parahaemolyticus isolates in Korea also showed RIF resistant phenotype (50.7\%). As a broad-spectrum antibiotic, SPT is often used in livestock and poultry breeding industry. In this study, about $25.5 \%$ of the isolates exhibited strong resistance phenotype against SPT, which was not detected previously. In addition, very few isolates exhibited tolerance to TM (1.25\%), KAN (1.00\%), CN (1.00\%), and SXT (0.75\%). Nevertheless, a high percentage of intermediate susceptibility to KAN was detected in the isolates $(70 \%)$, suggesting a potential resistance trend of this drug.

As shown in Fig. 2, our results also revealed distinct resistance patterns yielded by the $V$. parahaemolyticus isolates of different shrimp origins. AMP resistance was the most predominant among all the samples (97-100\%). High percentages of AMP resistance have also been observed in the bacterium isolated from $P$. monodon in India (Bhattacharya et al. 2000) and L. vannamei in Brazil (Rodrigues de Melo et al. 2011). In this study, the isolates derived from the P. monodon sample had the highest resistance levels against STR (73\%) and RIF (65\%) and also exhibited resistance to the maximum number of antimicrobial agents $(8 / 10)$, whereas those from M. rosenbergii showed an opposite pattern. In addition, the highest percentage of SPT resistance was detected from the isolates of E. carinicauda origin (52\%), which was notably higher than those from the other three samples (11-21\%). Moreover, the resistance to STR and RIF was the second abundant in the E. carinicauda strains, when compared to the other samples. To our knowledge, the comparative antibiotic resistance patterns of $V$. parahaemolyticus isolates have not been described in the four species of shrimps thus far.

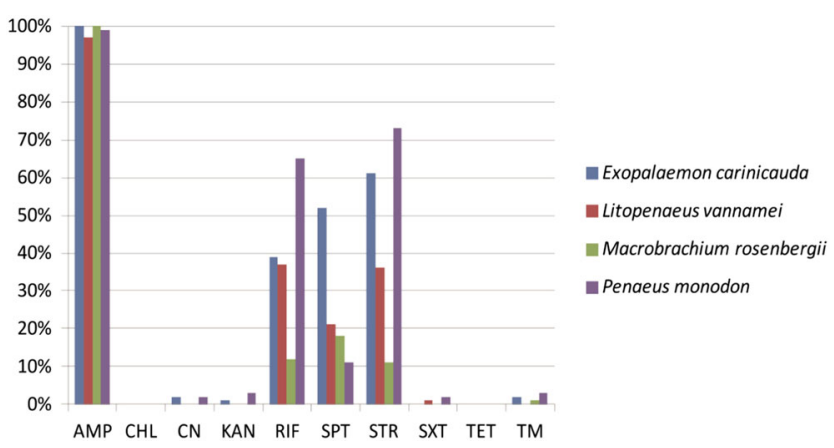

Fig. 2 Incidences of antibiotic resistant $V$. parahaemolyticus strains derived from the four different shrimp samples. $A M P$ ampicillin, $C H L$ chloramphenicol, $C N$ gentamicin, $K A N$ kanamycin, $R I F$ rifampicin, $S P T$ spectinomycin, $S T R$ streptomycin, $S X T$ sulfamethoxazole-trimethoprim, TET tetracycline, $T M$ trimethoprim
Moreover, this study constituted the first investigation of $V$. parahaemolyticus strains originated from M. rosenbergii and E. carinicauda.

Multidrug resistance (MDR) was defined as nonsusceptibility to at least one agent in three or more antimicrobial categories (Thapa Shrestha et al. 2015). MDR phenotypes have been observed in Vibrios derived from $L$. vannamei and P. monodon (de Melo et al. 2011; Albuquerque Costa et al. 2015). In this study, approximately $15.3 \%$ of the tested isolates exhibited MDR phenotypes, which varied depending on the shrimp samples. The strains derived from the P. monodon sample showed the highest occurrence of MDR (24\%), followed by 19,12 , and $6 \%$ from the E. carinicauda, $L$. vannamei, and $M$. rosenbergii samples, respectively (Fig. 3). Taken together, our data revealed the most prevalent antibiotic resistance among the $V$. parahaemolyticus isolates originating from $P$. monodon, which could be a result of serious contamination in this sample source. P. monodon is cultured in brackish water conditions, it will be interesting to trace back and investigate the possible reasons for the high prevalence of antibiotic resistance in future research.

\section{Tolerance of the $V$. parahaemolyticus isolates to heavy metals}

In this study, based on the antibiotic resistant results, a total of 90 selected antibiotic resistant $V$. parahaemolyticus isolates of the shrimp origin were further examined for their susceptibilities to heavy metals, including $\mathrm{Cd}^{2+}, \mathrm{Cr}^{3+}, \mathrm{Cu}^{2+}, \mathrm{Hg}^{2+}, \mathrm{Mn}^{2+}$, $\mathrm{Ni}^{2+}, \mathrm{Pb}^{2+}$, and $\mathrm{Zn}^{2+}$. As shown in Table 1, a maximum MIC of $3200 \mu \mathrm{g} / \mathrm{mL}$ for $\mathrm{Cd}^{2+}, \mathrm{Cr}^{3+}, \mathrm{Cu}^{2+}, \mathrm{Mn}^{2+}, \mathrm{Ni}^{2+}, \mathrm{Pb}^{2+}$, and

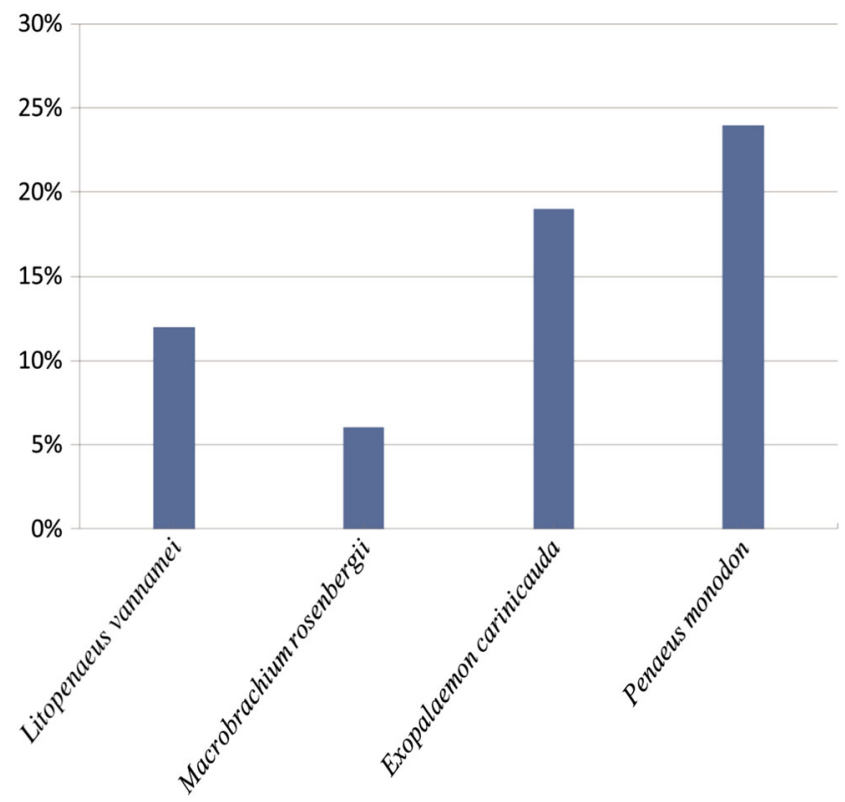

Fig. 3 Incidences of the MDR $V$. parahaemolyticus strains in the four different shrimp samples 
Table 1 Incidence of heavy metal resistance among the ninety V. parahaemolyticus isolates

\begin{tabular}{|c|c|c|c|c|c|c|c|c|c|c|c|c|}
\hline \multirow[t]{2}{*}{ Heavy metal } & \multicolumn{10}{|c|}{ MIC $(\mu \mathrm{g} / \mathrm{mL})$} & \multicolumn{2}{|c|}{ Resistant } \\
\hline & 6.25 & 12.5 & 25 & 50 & 100 & 200 & 400 & 800 & 1600 & 3200 & $n$ & $(\%)$ \\
\hline \multirow[t]{2}{*}{$\mathrm{Cd}$} & & & & & & & a & & & & & \\
\hline & & & & & & & 24 & 63 & 3 & & 66 & 73.3 \\
\hline \multirow[t]{2}{*}{$\mathrm{Cr}$} & & & & & & & & a & & & & \\
\hline & & & & & & & & & 49 & 41 & 90 & 100 \\
\hline \multirow[t]{2}{*}{$\mathrm{Cu}$} & & & & & & & & a & & & & \\
\hline & & & & & & & & 6 & 33 & 51 & 84 & 93.3 \\
\hline \multirow[t]{2}{*}{$\mathrm{Hg}$} & & a & & & & & & & & & & \\
\hline & 47 & 42 & 1 & 1 & & & & & & & 2 & 2.2 \\
\hline \multirow[t]{2}{*}{$\mathrm{Mn}$} & & & & & & & & & a & & & \\
\hline & & & & & & & 56 & 29 & 3 & 2 & 2 & 2.2 \\
\hline \multirow[t]{2}{*}{$\mathrm{Ni}$} & & & & & & & & a & & & & \\
\hline & & & & & & 2 & 1 & 81 & 5 & 1 & 6 & 6.7 \\
\hline \multirow[t]{2}{*}{$\mathrm{Pb}$} & & & & & & & & & a & & & \\
\hline & & & & & & & & & 11 & 79 & 79 & 87.8 \\
\hline \multirow[t]{2}{*}{$\mathrm{Zn}$} & & & & & & & $\mathrm{a}$ & & & & & \\
\hline & & & & & & & & 90 & & & 90 & 100 \\
\hline
\end{tabular}

${ }^{\text {a }}$ Minimal inhibition concentration of standard strain E. coli $\mathrm{K} 12$
$800 \mu \mathrm{g} / \mathrm{ml}$ for $\mathrm{Zn}^{2+}$ and $50 \mu \mathrm{g} / \mathrm{ml}$ for $\mathrm{Hg}^{2+}$ were observed, when compared to the quality control strain E. coli K12 (Malik and Aleem 2011). All the V. parahaemolyticus isolates were resistant to $\mathrm{Cr}^{3+}$ and $\mathrm{Zn}^{2+}$, the majority of which also displayed resistance to $\mathrm{Cu}^{2+}(93.3 \%), \mathrm{Pb}^{2+}(87.8 \%)$, and $\mathrm{Cd}^{2+}(73.3 \%)$. In addition, about $6.7 \%$ of the isolates showed resistance to $\mathrm{Ni}^{2+}$. It has been reported that the Yangtze River Estuary area has suffered heavy metal contamination, being located in one of the highest density of population and fastest economic developing areas in China (An et al. 2010; Zhao et al. 2012). Heavy-metal resistance has also been observed in Vibrios isolated from aquatic products and environment in the Yangze River estuary in Shanghai (Song et al. 2013). In this study, almost all the isolates were susceptible to $\mathrm{Mn}^{2+}$ and $\mathrm{Hg}^{2+}$, except those isolated from P. monodon and $L$. vannamei samples, where very low percentage of the isolates $(2.2 \%)$ was detected resistant to the two heavy metals (Fig. 4).

As shown in Fig. 4, the V. parahaemolyticus isolates derived from different shrimp sources had similar heavy-metal resistance patterns, most of which displayed resistance to $\mathrm{Cr}^{3+}, \mathrm{Cu}^{2+}$, and $\mathrm{Zn}^{2+}$ (90-100\%). Moreover, about 65.0$96.3 \%$ of the isolates showed resistance to $\mathrm{Pb}^{2+}$ and $\mathrm{Cd}^{2+}$, except the lower percentage of $\mathrm{Cd}^{2+}$ resistance in E. carinicauda $(37.5 \%)$. The results indicated that the sample sources appeared not greatly impact on the major heavy metal resistant patterns of $V$. parahaemolyticus. One possibility was that inappropriate release of industrial wastes may influence on different aquaculture environments.

In this study, our data indicated that the tolerance to heavy metals was very prevalent in the $V$. parahaemolyticus strains with more than two antibiotic resistance phenotypes. Industrial pollutants were supposed to enhance the selection for antibiotic resistance and vice versa (Bhattacharya et al. 2000; Baker-Austin et al. 2006; Malik and Aleem 2011). The abundant double-resistant bacteria could be a cause of serious concern due to the potential health impacts of consuming contaminated products (Holmström et al. 2003; Sharma et al. 2007).

\section{Phylogenetic relationships of the resistant V. parahaemolyticus isolates}

To track the relatedness of the 90 resistant isolates, we obtained their genome fingerprinting profiles (Fig. 5). Only three isolates could not be examined by the NotI-PFGE analysis in

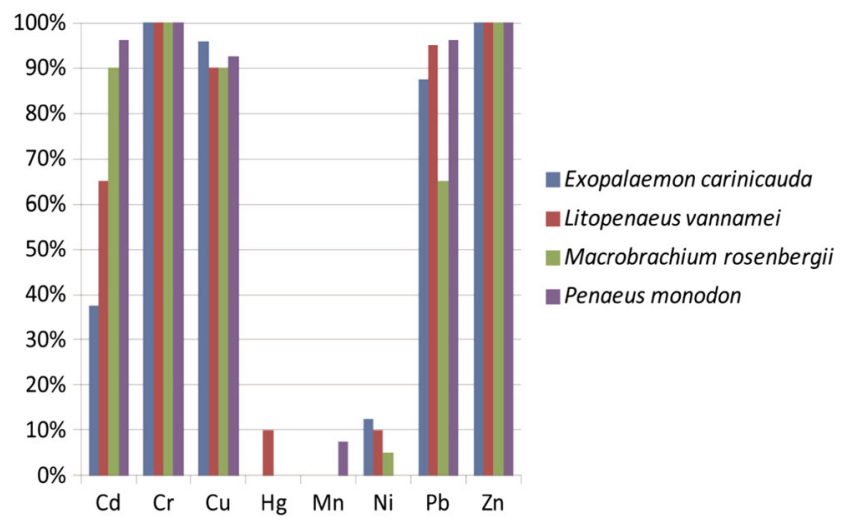

Fig. 4 Incidences of heavy metal resistant $V$. parahaemolyticus strains derived from the four different shrimp samples 
PFGE

PFGE

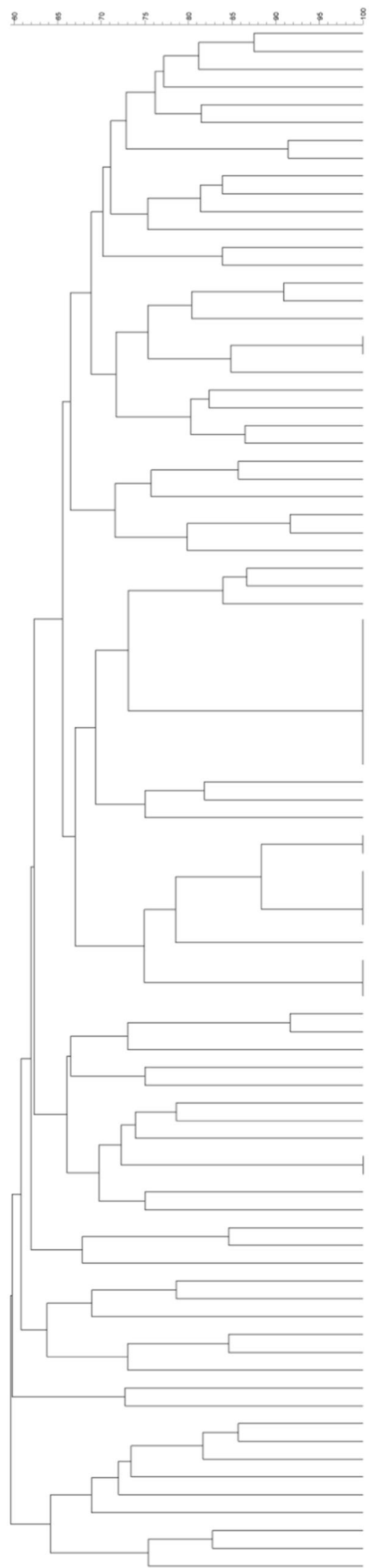

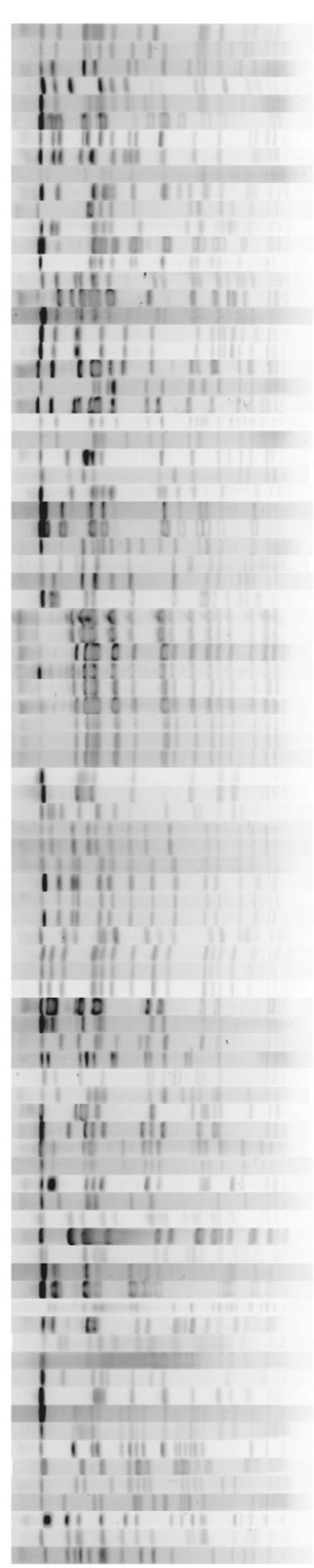

train

Chn 209

Chn239

Chn215

Chn207

Chn22

Chn228

Chn231

Chn 287

Chn28

Chn30

Chn226

Chn255

Chn289

Chn304

Chn268

Chn203

Chn222

Chn306

$\mathrm{Chn} 235$

Chn311

Chn230

Chn230

Chn233

Chn332

Chn285

Chn266

Chn291

Chn219

Chn201

Chn337

Chn202

Chn322

Chn323

Chn329

Chn321

Chn324

Chn327

Chn331

Chn 333

Chn335

Chn300

Chn301

Chn205

Chn334

Chn336

Chn206

Chn208

Chn212

Chn213

Chn286

Chn 204

Chn210

Chn237

Chn340

Chn340

Chn225
Chn234
Chn256

Chn325

Chn328

Chn326

Chn326

Chn339

Chn232
Chn298

$\mathrm{Chn} 30 \mathrm{~s}$

Chn292

Chn270

Chn270

Chn299

Chn283

Chn308

Chn227

Chn27

Chn297

Chn24

Chn248
Chn249
Chn273

Chn28

Chn236

Chn236

Chn242
Chn294
Chn338
Phenotyp

MDR

MDR

MDR

MDR

MDR
MDR

MDR

MDR

MOR

MDR

MDR

MDR

MDR

MDR

MDR

MD

MDR

MDR

MDR

MD

MDR

MDR

MDR

MDP

MDR

MDR

MDR

MDR

MOR

MDR
MDR

MDR

MDR

MDR

MDR

MDR
MDR
MDR

MDR

MDR

MDR
MDR

MDR

\begin{tabular}{|c|c|c|}
\hline Source & Pulsotype & Cluster \\
\hline Litopenaeus vannamei & Vpchn00001 ᄀ & \\
\hline Penaeus monodon & Vpchn00002 & \\
\hline Litopenaeus vannamei & Vpchn00003 & \\
\hline Litopenaeus vannamei & Vpchn00004 & \\
\hline Litopenaeus vannamei & Vpchn00005 & \\
\hline Macrobrachium rosenbergii & Vpchn00006 & \\
\hline Macrobrachium rosenbergif & Vpchn00007 & \\
\hline Exopalaemon carinicauda & Vpchn00008 & \\
\hline Macrobrachium rosenbergï & Vpchn00009 & \\
\hline Exopalaemon carinicauda & Vpchn00010 & \\
\hline Exopalaemon carinicauda & Vpchn00011 & \\
\hline Exopalaemon carinicauda & Vpchn00012 & \\
\hline Macrobrachium rosenbergii & Vpchn00013 & \\
\hline Penaeus monodon & Vpchn00014 & A \\
\hline Exopalaemon carinicauda & Vpchn00015 & \\
\hline Exopalaemon carinicauda & Vpchno0016 & \\
\hline Macrobrachium rosenbergif & Vpchn00017 & \\
\hline Litopenaeus vannamei & Vpchn00018 & \\
\hline Litopenaeus vannamei & Vpchn00018 & \\
\hline Exopalaemon carinicauda & Vpchn00019 & \\
\hline Macrobrachium rosenbergif & Vpchn00020 & \\
\hline Exopalaemon carinicauda & Vpchn00021 & \\
\hline Macrobrachium rosenbergif & Vpchn00022 & \\
\hline Macrobrachium rosenbergif & Vpchn00023 & \\
\hline Litopenaeus vannamei & Vpchn00024 & \\
\hline Penaeus monodon & Vpchno0025 & \\
\hline Exopalaemon carinicauda & Vpchn00026 & \\
\hline Macrobrachium rosenbergii & Vpchn00027 & \\
\hline Exopalaemon carinicauda & Vpchn00028 & \\
\hline Litopenaeus vannamei & Vpchno0029 - & \\
\hline Litopenacus vannamei & Vpchno0030 - & \\
\hline Peneeus monodon & Vpchn00031 & \\
\hline Litopenaeus vannamei & Vpchn00032 & \\
\hline Peneeus monodon & Vpchn00033 & \\
\hline Penaeus monodon & Vpchn00033 & \\
\hline Penaeus monodon & Vpchn00033 & \\
\hline Penaeus monodon & Vpchn00033 & B \\
\hline Penaeus monodon & Vpchn00033 & \\
\hline Penaeus monodon & Vpchn00033 & \\
\hline Penaeus monodon & Vpchno0033 & \\
\hline Penaeus monodon & Vpchn00033 & \\
\hline Penaeus monodon & Vpchn00033 & \\
\hline Exopalaemon carinicauda & Vpchn00034 & \\
\hline Exopalaemon carinicauda & Vpchn00035 & \\
\hline Litopenaeus vannamei & Vpchn00036 - & \\
\hline Peneeus monodon & Vpchn00037- & \\
\hline Penaeus monodon & Vpchn00037 & \\
\hline Litopenaeus vannamei & Vpchn00038 & \\
\hline Litopenaeus vannamei & Vpchn00038 & \\
\hline Litopenaeus vannamei & Vpchn00038 & C \\
\hline Litopenaeus vannamei & Vpchn00038 & \\
\hline Exopa/aemon carinicauda & Vpchn00039 & \\
\hline Litopenaeus vannamei & Vpchn00040 & \\
\hline Litopenaeus vannamei & Vpchn000040 & \\
\hline Litopenaeus vannamei & Vpchn00040 & \\
\hline Litopenaeus vannamei & Vpchn00041 - & \\
\hline Macrobrachium rosenbergif & Vpchn00042 - & \\
\hline Penaeus monodon & Vpchn00043 & \\
\hline Macrobrachium rosenbergif & Vpchn00044 & \\
\hline Macrobrachium rosenbergif & Vpchn000045 & \\
\hline Penaeus monodon & Vpchn00046 & \\
\hline Penaeus monodon & Vpchn00047 & D \\
\hline Penaeus monodon & Vpchn00048 & \\
\hline Penaeus monodon & Vpchn00049 & \\
\hline Penaeus monodon & Vpchn00049 & \\
\hline Litopenaeus vannamei & Vpchn00050 & \\
\hline Macrobrachium rosenbergii & Vpchno0051 & \\
\hline Exopa/aemon carinicauda & Vpchn00052- & \\
\hline Exopalaemon carinicauda & Vpchn00053 & $\mathrm{E}$ \\
\hline Exopalaemon carinicauda & Vpchn00054 - & \\
\hline Macrobrachium rosenbergï & Vpchn00055- & \\
\hline Exopalaemon carinicauda & Vpchn00056 & \\
\hline Macrobrachium rosenbergii & Vpchn00057 & \\
\hline Exopalaemon carinicauda & Vpchn00058 & $\mathrm{F}$ \\
\hline Exopalaemon cerinicaude & Vpchn00059 & \\
\hline Macrobrachium rosenbergif & Vpchno0060- & \\
\hline Macrobrachium rosenbergif & Vpchn00061 & G \\
\hline Exopalaemon carinicauda & Vpchno0062 - & \\
\hline Penaeus monodon & Vpchno0063 - & \\
\hline Penaeus monodon & Vpchn00064 & \\
\hline Penaeus monodon & Vpchn00065 & \\
\hline Macrobrachium rosenbergif & Vpchno0006 & \\
\hline Exopalaemon carinicauda & Vpchn00067 & $\mathrm{H}$ \\
\hline Macrobrachium rosenbergif & Vpchn00068 & \\
\hline Penaeus monodon & Vpchn00069 & \\
\hline Exopalaemon carinicauda & Vpchn00070 & \\
\hline Peneeus monodon & Vpchn00071 & \\
\hline
\end{tabular}

Fig. 5 The PFGE-base genotyping of the V. parahaemolyticus strains in this study 
this study. Given the significant difference of a single DNA band in size ranging from 20.5 to $1135 \mathrm{~kb}$ on the PFGE gels, cluster analysis of the NotI-PFGE profiles revealed a total of 71 pulsotypes. Five pairs of isolates and one group of six isolates clustered at $\geq 87 \%$ similarity, which is a cut-off value that has been suggested for use in identifying isolates belonging to the same epidemic strain (Seifert et al. 2005). The majority of the isolates $(81.6 \%)$ shared $60-87 \%$ similarity in this study. In addition, all the isolates were assigned into eight distinct clusters, among which the majority of the isolates $(89.7 \%)$ into Cluster A to $\mathrm{G}$, whereas nine isolates into Cluster $\mathrm{H}$, which was more distantly related with the formers (Fig. 5). These results demonstrated that the V.parahaemolyticus isolates varied considerably, with remarkable genetic diversity existing in the tested shrimp samples.

Notably, all the isolates originating from the $L$. vannamei sample fell into Clusters A to C, except one into Cluster D. Similarly, the majority of the isolates $(80.8 \%)$ derived from P. monodon were grouped into Clusters $\mathrm{A}$ to $\mathrm{D}$, with the remaining isolates belonging to Cluster $\mathrm{H}$. Moreover, nine and two isolates from P. monodon exhibited $100 \%$ similarity and fell into the same pulsotypes of Vpchn00033 and Vpchn00037, respectively. These results indicated more closely relationships of $V$. parahaemolyticus between $L$. vannamei and P. monodon, when compared to the other samples, in which the isolates belonging to seven of the eight PFGE clusters were identified (Fig. 5).

In addition, the isolates with MDR phenotypes that were derived from all the tested samples were distributed among the PFGE clusters. Based on the value of Simpson's diversity index (0.9872), these isolates appeared to have the greater diversity in the $V$. parahaemolyticus population. As described above, the 90 isolates were resistant to $\mathrm{Cr}^{3+}$ and $\mathrm{Zn}^{2+}$, the majority of which also displayed resistance to $\mathrm{Cu}^{2+}(93.3 \%), \mathrm{Pb}^{2+}(87.8 \%)$, and $\mathrm{Cd}^{2+}$ (73.3 \%). The antibiotic and heavy-metal resistance phenotypes were widely distributed among the PFGE clusters with no significant relevance with the PFGE clusters, suggesting that resistance determinants perhaps spread among many genetic lineages within the $V$. parahaemolyticus population, regardless of different sample origins.

V. parahaemolyticus harbors two chromosomes (Makino et al. 2003). Mobile genetic elements carrying resistance genes have been identified from the bacterium (e.g., Song et al. 2013), which might be responsible for the large degree of variation in genotypes and resistance phenotypes among the isolates. It will be interesting to elucidate the precise mechanisms underlying the transmission of resistance determinants in $V$. parahaemolyticus population in the future research.

\section{Conclusions}

In this study, a total of $400 \mathrm{~V}$. parahaemolyticus isolates from commonly consumed fresh shrimps in Shanghai fish markets,
China in 2013-2014 were isolated and characterized. Our data revealed an extremely low incidence of pathogenic $V$. parahaemolyticus carrying the two genes coding for the major virulence factors (tdh and trh, 0.0 and $0.5 \%$ ). However, high levels of antibiotic resistance were observed among the isolates against ampicillin (99\%), streptomycin (45.25\%), rifampicin (38.25\%), and spectinomycin $(25.50 \%)$. Moreover, approximately $15.3 \%$ of the isolates exhibited MDR phenotypes. In addition, tolerance to heavy metals of $\mathrm{Cr}^{3+}$ and $\mathrm{Zn}^{2+}$ was observed in 90 antibiotic-resistant isolates, the majority of which also displayed resistance to $\mathrm{Cu}^{2+}(93.3 \%), \mathrm{Pb}^{2+}(87.8 \%)$, and $\mathrm{Cd}^{2+}(73.3 \%)$, when compared to E. coli $\mathrm{K} 12$. The PFGE-based genotyping of these isolates revealed a total of 71 pulsotypes, demonstrating remarkable genetic diversity of $V$. parahaemolyticus population in the shrimp samples, with the co-existence and wide distribution of a number of resistant isolates. The results also revealed the most contaminated reservoir of MDR $V$. parahaemolyticus in the P. monodon sample. The data in this study will refine our grasp of $V$. parahaemolyticus molecular ecology in aquaculture products and enable appropriate food-borne disease-control in aquaculture industry.

Acknowledgments This work was supported by the grants from the Shanghai Municipal Education Commission (no. B-9500-10-0004) and National Nature Science Foundation of China (no. 31271830).

Open Access This article is distributed under the terms of the Creative Commons Attribution 4.0 International License (http:// creativecommons.org/licenses/by/4.0/), which permits unrestricted use, distribution, and reproduction in any medium, provided you give appropriate credit to the original author(s) and the source, provide a link to the Creative Commons license, and indicate if changes were made.

\section{References}

Albuquerque Costa R, Araújo RL, Souza OV, Vieira RH (2015) Antibiotic-resistant Vibrios in farmed shrimp. Biomed Res Int 2015:505914

An Q, Wu YQ, Wang JH, Li ZE (2010) Assessment of dissolved heavy metal in the Yangtze river estuary and its adjacent sea, China. Environ Monit Assess 164:173-187

Ansari MI, Grohmann E, Malik A (2008) Conjugative plasmids in multiresistant bacterial isolates from Indian soil. J Appl Microbiol 104: $1774-1781$

Baker-Austin C, Wright MS, Stepanauskas R, McArthur JV (2006) Coselection of antibiotic and metal resistance. Trends Microbiol 14: 176-182

Baumann P, Baumann L, Reichelt JL (1973) Taxonomyof marine bacteria: Beneckeaparahaemolytica and Beneckeaalginolytica. J Bacteriol 113:1144-1155

Bhattacharya M, Choudhury P, Kumar R (2000) Antibiotic-and metalresistant strains of Vibrio parahaemolyticus isolated from shrimps. Microb Drug Resist 6:171-172 
Boyd EF, Cohen AL, Naughton LM, Ussery DW, Binnewies TT, Stine OC, Parent MA (2008) Molecular analysis of the emergence of pandemic Vibrio parahaemolyticus. BMC Microbiol 8:110

Broberg CA, Calder TJ, Orth K (2011) Vibrio parahaemolyticus cell biology and pathogenicity determinants. Microbes Infect 13:9921001

Ceccarelli D, Hasan NA, Huq A, Colwell RR (2013) Distribution and dynamics of epidemic and pandemic Vibrio parahaemolyticus virulence factors. Front Cell Infect Microbiol 3:97. doi:10.3389/fcimb. 00097

Chao G, Jiao X, Zhou X, Yang Z, Huang J, Zhou L, Qian X (2009) Distribution, prevalence, molecular typing, and virulence of Vibrio parahaemolyticus isolated from different sources in coastal province Jiangsu, China. Food Control 20:907-912

Chen Y, Guo Y, Wang Z, Liu X, Liu H, Dai Y, Tang Z, Wen J (2010) Foodborne disease outbreaks in 2006 report of the National Foodborne Disease Surveillance Network, China. J Hygiene Res 39:331-334

Chen W, Xie Y, Xu J, Wang Q, Gu M, Yang J, Zhou M, Wang D, Shi C, Shi X (2012) Molecular typing of Vibrio parahaemolyticus isolates from the middle-east coastline of China. Int J Food Microbiol 153: 402-412

de Melo LM, Almeida D, Hofer E, Dos Reis CM, Theophilo GN, Santos AF, Vieira RH (2011) Antibiotic resistance of Vibrio parahaemolyticus isolated from pond-reared Litopenaeus vannamei marketed in Natal, Brazil. Braz J Microbiol 42:1463-1469

Fujino T, Miwatani T, Yasuda J, Kondo M, Takeda Y, Akita Y, Kotera K, Okada M, Nishimune H, Shimizu Y, Tamura T, Tamura Y (1965) Taxonomic studies on the bacterial strains isolated from cases of "shirasu" food-poisoning (Pasteurella parahaemolytica) and related microorganisms. Biken J 8:63-71

Haley BJ, Kokashvili T, Tskshvediani A, Janelidze N, Mitaishvili N, Grim CJ, Constantin de Magny G, Chen AJ, Taviani E, Eliashvili T, Tediashvili M, Whitehouse CA, Colwell RR, Huq A (2014) Molecular diversity and predictability of Vibrio parahaemolyticus along the Georgian coastal zone of the Black Sea. Front Microbiol 5:45

He Y, Wang H, Chen L (2015) Comparative secretomics reveals novel virulence-associated factors of Vibrio parahaemolyticus. Front Microbiol. doi:10.3389/fmicb

Holmström K, Gräslund S, Wahlström A, Poungshompoo S, Bengtsson BE, Kautsky N (2003) Antibiotic use in shrimp farming and implications for environmental impacts and human health. Int J Food Sci Technol 38:255-266

Kang CH, Shin Y, Kim W, Kim Y, Song K, Oh EG, Kim S, Yu H, So JS (2015) Prevalence and antimicrobial susceptibility of Vibrio parahaemolyticus isolated from oysters in Korea. Environ Sci Pollut R. doi:10.1007/s11356-015-5650-9

Letchumanan V, Chan KG, Lee LH (2014) Vibrio parahaemolyticus: a review on the pathogenesis, prevalence, and advance molecular identification techniques. Front Microbiol 5:705

Lopatek M, Wieczorek K, Osek J (2015) Prevalence and antimicrobial resistance of Vibrio parahaemolyticus isolated from raw shellfish in Poland. J Food Protect 78:1029-1033

Makino K, Oshima K, Kurokawa K, Yokoyama K, Uda T, Tagomori K, Iijima Y, Najima M, Nakano M, Yamashita A, Kubota Y, Kimura S, Yasunaga T, Honda T, Shinagawa H, Hattori M, Iida T (2003) Genome sequence of Vibrio parahaemolyticus: a pathogenic mechanism distinct from that of $V$. cholerae. Lancet 361:743-749

Malik A, Aleem A (2011) Incidence of metal and antibiotic resistance in Pseudomonas spp. from the river water, agricultural soil irrigated with wastewater and groundwater. Environ Monit Assess 178:293-308
Matyar F (2012) Antibiotic and heavy metal resistance in bacteria isolated from the Eastern Mediterranean Sea coast. B Environ Contam Tox 89:551-556

Nunan LM, Lightner DV, Oduori MA, Gasparich GE (2005) Spiroplasma penaei sp. nov., associated with mortalities in Penaeus vannamei, Pacific whiteshrimp. Int J Syst Evol Microbiol 55(Pt 6):2317-22

Ottaviani D, Leoni F, Talevi G, Masini L, Santarelli S, Rocchegiani E, Susini F, Montagna C, Monno R, D’Annibale L, Manso E, Oliva M, Pazzani C (2013) Extensive investigation of antimicrobial resistance in Vibrio parahaemolyticus from shellfish and clinical sources, Italy. Int J Antimicrob Ag 42:191-193

Sabry SA, Ghozalan HA, Abou-Zeid DM (1997) Metal tolerance and antibiotic resistance patterns of a bacterial population isolated from sea water. J Appl Microbiol 62:245-252

Sahul Hameed AS, Bonami JR (2012) White tail disease of freshwater prawn, Macrobrachium rosenbergii. Indian J Virol 23(2):134-40

Seifert H, Dolzani L, Bressan R, van der Reijden T, van Strijen B, Stefanik D, Heersma H, Dijkshoorn L (2005) Standardization and interlaboratory reproducibility assessment of pulsed-field gel electrophoresis-generated fingerprints of Acinetobacter baumannii. J Clin Microbiol 43:4328-4335

Sharma RK, Agrawal M, Marshall F (2007) Heavy metal contamination of soil and vegetables in suburban areas of Varanasi, India. Ecotoxicol Environ Safety 66:258-266

Song Y, Yu P, Li B, Pan Y, Zhang X, Cong J, Zhao Y, Wang H, Chen L (2013) The mosaic accessory gene structures of the SXT/R391-like integrative and conjugative elements derived from Vibrio spp. isolated from aquatic products and environment in the Yangtze River Estuary, China. BMC Microbiol 13:214

Tang Y, Tao P, Tan J, Mu H, Peng L, Yang D, Tong S, Chen L (2014) Identification of bacterial community composition in freshwater aquaculture system farming of Litopenaeus vannamei reveals distinct temperature-driven patterns. Int J Mol Sci 15:13663-13680

Thapa Shrestha U, Adhikari N, Maharjan R, Banjara MR, Rijal KR, Basnyat SR, Agrawal VP (2015) Multidrug resistant Vibrio cholerae $\mathrm{O} 1$ from clinical and environmental samples in Kathmandu city. BMC Infect Dis 15:104

Tsai SE, Jong KJ, Tey YH, Yu WT, Chiou CS, Lee YS, Wong HC (2013) Molecular characterization of clinical and environmental Vibrio parahaemolyticus isolates in Taiwan. Int J Food Microbiol 165: $18-26$

Wang S, Duan H, Zhang W, Li JW (2007) Analysis of bacterial foodborne disease outbreaks in China between 1994 and 2005. FEMS Immunol Med Mic 51:8-13

Woolhouse M, Farrar J (2014) Policy: an intergovernmental panel on antimicrobial resistance. Nature 509:555

Wu Y, Wen J, Ma Y, Ma X, Chen Y (2014) Epidemiology of foodborne disease outbreaks caused by Vibrio parahaemolyticus, China, 20032008. Food Control 46:197-202

Xie T, Wu Q, Xu X, Zhang J, Guo W (2015) Prevalence and population analysis of Vibrio parahaemolyticus in aquatic products from South China markets. FEMS Microbiol Lett. doi:10.1093/femsle/fnv178

Xu X, Wu Q, Zhang J, Cheng J, Zhang S, Wu K (2014) Prevalence, pathogenicity, and serotypes of Vibrio parahaemolyticus in shrimp from Chinese retail markets. Food Control 46:81-85

Zhang XZ, Cheng XQ, Yu YX, Shen H, Wan XH (2015) Analysis of ITS1 sequences and genetic relationships between populations of ridgetail white prawn, Exopalaemon carinicauda, in the East China Sea. Genet Mol Res 14(4):12316-12322

Zhao S, Feng C, Quan W, Chen X, Niu J, Shen Z (2012) Role of living environments in the accumulation characteristics of heavy metals in fishes and crabs in the Yangtze river estuary, China. Mar Pollut Bull 64:1163-1171 